incidence, anatomic characteristics, and outcomes. J Thorac Cardiovasc Surg. 2022; 163:1156-62.

3. LaCorte MA, Cooper MS, Kauffman SL, Schiller MS, Golinko RJ, Griepp RG. Atrioventricular canal ventricular septal defect with cleft mitral valve. Angiographic and echocardiographic features. Pediatr Cardiol. 1982;2:289-95.

4. Lopez L, Houyel L, Colan SD, Anderson RH, Beland MJ, Aiello VD, et al. Classification of ventricular septal defects for the eleventh iteration of the international classification of diseases_-striving for consensus: a report from the International
Society for Nomenclature of Paediatric and Congenital Heart Disease. Ann Thorac Surg. 2018;106:1578-89.

5. Spicer DE, Anderson RH, Backer CL. Clarifying the surgical morphology of inlet 446 ventricular septal defects. Ann Thorac Surg. 2013;95:236-41.

6. Yoshitake S, Kaneko Y, Morita K, Hoshino M, Nagashima M, Takahashi M, et al Reassessment of the location of the conduction system in atrioventricular septal defect using phase-contrast computed tomography. Semin Thorac Cardiovasc Surg. 2020;32:860-8.
See Article page 1156.

\section{Commentary: Beware the AVSD with no "A"}

\section{Carl L. Backer, MD}

Kwon and colleagues ${ }^{1}$ from Seattle Children's have provided an interesting review of a unique subgroup of patients with atrioventricular septal defect (AVSD). These are the patients with AVSD and no "A"; that is, AVSD with an absent or very small atrial component but still a common atrioventricular junction with a common $\mathrm{AV}$ valve. In their series of 249 patients with AVSD, only $16(6 \%)$ had either no atrial component or a diminutive atrial component. This unique group of patients demonstrates how truly varied morphologic phenotypes can exist within the genotype of AVSD.

The authors describe important surgical caveats for surgeons to consider when encountering patients with this variant of AVSD. The first is that when presented with a patient with an inlet muscular VSD and mitral valve insufficiency, a surgeon should be suspicious and be prepared to deal with this particularly unique anatomy. Closing a simple inlet VSD with a patch is a much different operation than repairing a complete AVSD with no atrial component.

\footnotetext{
From the Section of Pediatric Cardiothoracic Surgery, UK HealthCare Kentucky Children's Hospital, Lexington, Ky; and Cardiothoracic Surgery Department, Heart Institute, Cincinnati Children's Hospital Medical Center, Cincinnati, Ohio. Disclosures: The author reported no conflicts of interest.

The Journal policy requires editors and reviewers to disclose conflicts of interest and to decline handling or reviewing manuscripts for which they may have a conflict of interest. The editors and reviewers of this article have no conflicts of interest.

Received for publication June 24, 2021; revisions received June 24, 2021; accepted for publication June 25, 2021; available ahead of print July 1, 2021.

Address for reprints: Carl L. Backer, MD, Section of Pediatric Cardiothoracic Surgery, UK HealthCare Kentucky Children's Hospital, 800 Rose St, C-259, Lexington, KY 40536-0293 (E-mail: Carl.Backer@uky.edu).

J Thorac Cardiovasc Surg 2022;163:1164-5

$0022-5223 / \$ 36.00$

Copyright (c) 2021 by The American Association for Thoracic Surgery

https://doi.org/10.1016/j.jtcvs.2021.06.057
}

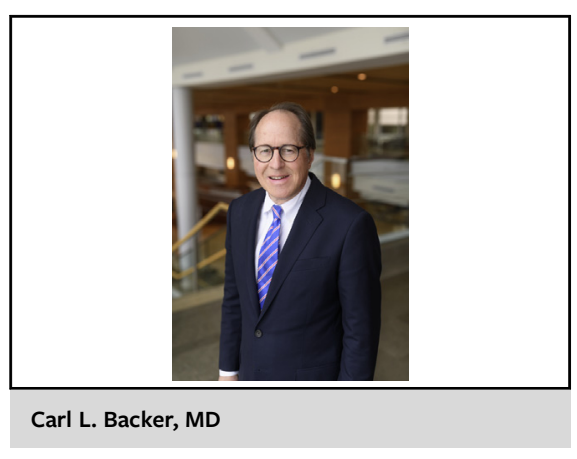

CENTRAL MESSAGE

Children with AVSD can present with a common AV junction, but no atrial component. These patients will have a technically challenging left AV valve repair and other anatomic nuances that are reviewed here.

The next surgical lesson is that adequate exposure to assess the anatomy and effect a durable repair nearly always requires opening the atrial septum. As the authors note, it is quite safe to incise the atrial septum through the fossa ovalis inferiorly and then at $90^{\circ}$ from the midpoint of this incision toward the common AV valve without causing AV block. This is by far the best way to assess the left AV valve and close the cleft or as some prefer to call it, the zone of apposition.

Another surgical issue pointed out by the authors and something I have noted in patients I have operated on is that it is not uncommon in this group to have chordae crossing from the left ventricle to support the right AV valve. Being prepared to encounter these crossing cords enables a surgeon to be ready to cut secondary cords not needed for AV valve competence that interfere with closure of the VSD. 
It also appears from the authors' experience that the strategy of repositioning the atrial septum rightward is actually fraught with risk and now not recommended. All 3 patients in whom this was attempted required reoperation on the left $\mathrm{AV}$ valve and 1 of these patients (the only 1 in the series) developed heart block and eventually died from multiple complications. The reasoning given behind repositioning the atrial septum was to prevent left $\mathrm{AV}$ valve stenosis. The authors now recommend leaving the atrial septum in its original location and erring on the side of potentially leaving some left AV valve stenosis, which is generally well tolerated. The authors also recommend closing the cleft as completely as possible at the time of the initial repair to minimize left $\mathrm{AV}$ valve insufficiency.
This type of review that accurately characterizes a unique group of rare congenital cardiac anomalies is extremely helpful to surgeons to achieve the best possible outcome and not repeat prior misadventures. It is clear that patients with AVSD in which the primum component is absent or diminutive have a much more technically challenging left AV valve repair. Being forewarned and prepared to deal with this anatomic variant is to be forearmed.

\section{Reference}

1. Kwon MH, Schultz AH, Lee ME, Permut LC, McMullan M, Nuri MK. Complete atrioventricular septal defect with absent or diminutive primum component: incidence, anatomic characteristics, and outcomes. J Thorac Cardiovasc Surg. 2022; 163:1156-62 